\title{
Language Experience Approach in Teaching Reading Comprehension to the Engineering Students
}

\author{
Zulkifli $^{1 *}$, Nian Masna Evawati ${ }^{1}$, Koryati $^{1}$ \\ ${ }^{1}$ English Department,State Polytechnic of Sriwijaya, Palembang, Indonesia \\ *Corresponding author. Email: zulzulkiflierwin@yahoo.com
}

\begin{abstract}
The main purpose of this study is to find out whether or not the students who were taught by using the Language Experience Approach (LEA) gained better achievement in reading comprehension that those who were taught by using the traditional approach. The method used in this study was experimental method. The population was the third semester of engineering students of state Polytechnic of Sriwijaya i the academic year of 2018/2019. The total number of the population was 176 . The sample of the study was 52 students. The y were divided into two groups: group A was taught by using the LEA and group B was taught by using traditional approach. The findings of this study indicate that teaching reading through the LEA better result than did the traditional approach in terms of students' reading comprehension achievement. The result of this study is expected to be an important input for the teacher of English to develop the students' motivation and reading ability. In order to generalize the finding of this study, a further research conducted in the wider population and longer time should be done
\end{abstract}

Keywords: strategy, LEA, reading comprehension

\section{INTRODUCTION}

Reading is an activity of absorbing information from all readable sources. It is an active process consisting of recognition and comprehension skill [1]. By having comprehension, someone can be claimed that he has done the process of reading, and get information stated in the text. [2] states that comprehension is the essence of reading because the goal of written language is communication of messages. If we do not understand the message, we are not reading. In other words, comprehension is the important aspect of reading. Unfortunately, the students cannot comprehend English texts well. They are difficult to recognize the information of the text or answering the comprehensive questions. It also happened in the third semester of engineering students in State Polytechnic of Sriwijaya

Reading comprehension is the ability to process text, understand its meaning, and to integrate with what the reader already knows [3]. Fundamental skills required in efficient reading comprehension are knowing meaning of words, ability to understand meaning of a word from discourse context, ability to follow organization of passage and to identify antecedents and references in it, ability to draw inferences from a passage about its contents, ability to identify the main thought of a passage, ability to answer questions answered in a passage, ability to recognize the literary devices or propositional structures used in a passage and determine its tone, and finally ability to determine writer's purpose,
An individual's ability to comprehend text is influenced by their skills and their ability to process information. If word recognition is difficult, students use too much of their processing capacity to read individual words, which interferes with their ability to comprehend what is read. There are a number of reading strategies to improve reading comprehension and inferences, including improving one's vocabulary, critical text analysis and practicing deep reading [4].

Realizing the important of reading, the teacher of English should consider what kind of approaches he or she should use. It is the teacher's task to choose an approach for the students because there are a variety of approaches to reading instruction employed in classroom activities. [5] states that students learn to read by a number of approaches and classroom settings, so no type of approach can be claimed as the best. The teacher may apply and modify some different approaches to meet the students' needs. [6] state that the effective teacher of reading is not only knowledgeable regarding different approaches but also understands the necessity to use parts of various approaches to meet children's needs.

One of the ways to make the reading materials both interesting and comprehensible to the students is by using students own writing as the reading materials. This reading approach has been known well as the language Experience Approach (LEA). According to [7] this reading approach does not only decrease the reading inability but also motivate students to want to read. Students will find the text much easier to read and understand because they use vocabulary and language patterns which are already familiar to them. Therefore, the reading text becomes a 
useful point for teaching reading and language skills [8]. [7] mention several strengths of the LEA: (a) Students language is used as the basis for reading instruction, (b) Students are motivated because of the high level of interest, (c) Students oral language skills are promoted, and (d) Students become aware of the language, reading and writing connection.

Actually, there are variations of the LEA activities, but in all its forms the central LEA concepts remain the sameusing the students own vocabulary language pattern, and background knowledge to create the reading text make reading a meaningful process. The extention of the LEA in teaching reading comprehension is the extending concept through language activities approach [8].

There are three reasons that encouraged the writer to choose this topic. First of all, in mechanical engineering curriculum, reading becomes the focus among the four language skills; listening, speaking, reading and writing. It is also stated that these four components should be presented as an integrated activity so the students will find supports from one another. The LEA in teaching reading comprehension involves the students writing, speaking, and listening skill. It means that this reading approach matches the engineering curriculum of State polytechnic of Sriwijaya. Secondly, the topic in the LEA activities encouraged the writer to apply this reading approach. After reading many books and articles which talk about the advantages of using the LEA in teaching reading comprehension, it was assumed that this reading approach had been successfully tried out for.

\section{LITERATURE REVIEW}

\subsection{Reading}

According to [8] reading is a primary means of language acquisition. Through reading, people will get many profits like knowing new development or information, adding their knowledge, and having pleasure. The word "reading" has complex definition. One simple definition will not be enough to explain it. The definition can be supported too by other definitions given by other experts of reading. [6] define that 1 . Reading is interacting with language that has been coded into print. 2 . The product of interacting with the printed language should be comprehension. 3. Reading is an active and on going process that is affected directly by an individual's interaction with his environment.

Meanwhile, [11] states that reading is an active cognitive process of interacting with print and monitoring comprehension to establish meaning. It can also be said that reading functions as the act of responding with appropriate meaning to written materials. It means that reading is the process of the reader in interpreting the writer's message through printed materials. When a reader interacts with print, his/her prior knowledge combined with the visual (written) information results in his/her comprehension [11]. It means that our ability to understand what we are reading is based on our reconstruction of the meaning behind a printed word. Such recognition is based on our previous experiences with the topic, our familiarity with its main concepts and our general knowledge of how language works.

\subsection{The Teaching of Reading}

In teaching and learning reading, reading approaches play an important role because they facilitate students to read efficiently. Therefore, the teacher of English should select such approaches which best suit his or her students' particular purpose. The selection of the approaches should primarily depend on the students' needs. Since there is no specific approach which is best for all students or all reading situations, the teacher must be knowledgeable regarding different approaches. His or her skill and personality are the instrument that create the condition for learning. However, the teacher should always remember that he or she should deal with the language as a whole, not just some aspects or skills only, so the students will find that each language skill supports one another. And the guidelines for effective second and foreign language learning is through in integrated English instruction [11]. Language is best acquired in setting where there is a need to know, the chance to try, and the freedom to fail without a penalty. Second and foreign language acquisition also take place most effectively in formal, real life settings where the learner is freely interacting with the teacher. It means that the teacher of English should provide opportunities for his or her students to use English in a natural, supportive, and mistakes.

\subsection{The Concept of the LEA}

Lexically, concept means an idea underlying a class of thing or general notion. [12] claims "Concept is the general idea or abstraction which is associated with word or symbol in person's mind. It is a group of stimuli with common characteristics."

The concept of the LEA means' a general idea or notion about what the LEA is in order to gain a unified concept about the LEA, the following notions can be considered.

\subsubsection{Historical Background}

Various approaches for teaching reading as a second or foreign languages have been developed over the years. And for many years, linguists have recognized the worth of the students' language and experiences as basic ingredients in reading instruction. The use of students' language and experiences in teaching reading was first devised in San Diego in which some schools used in stories dictated by the students and written down by the teacher as beginning reading materials. Then, Edmund Huey reported the use of sentence method which drew 
upon the students is language and experiences to describe pictures. And through the first half of this century, numerous educators cited and recommended an experience based approach to teaching reading. In recent years, interest in using the language and experiences of the students have continued to grow. The approach became widely recognizes and identified as The Language experience Approach (LEA).

Since then, the LEA has become the flexible reading approach. Adaptations and variations of the LEA have been explored by many linguists. Such adaptations and variations are designed to meet student needs. It means that the LEA can be used with students of all ages and abilities [13].

\subsubsection{The Activities of the LEA}

As mentioned before, the LEA is a flexible reading approach and there are many variations of the LEA. In addition, Bromley [11] supports that the LEA is a highly for motivating and personal approach with much potential for flexibility and creativity. LEA has the advantage of following great flexibility in organizing school activities for the teachers can work with the entire class, small group, and/or individual.

On the basis of the statements above, the LEA program allows each teacher to suit instruction to the specific needs and interest of students. The exact procedure to be followed may be modified in numerous ways. It also means that the LEA can be used with students of all ages and abilities. To use the LEA, a teacher can use a variety of techniques for getting the material from the students in their language. According to [7], there are three options in taking the material from the students: (a) students dictate, teacher writes the ideas on a sheet paper, but then the students copy the ideas into their books; (b) students dictate their ideas and teacher records them in the students books; and (c) those students who are capable, write their ideas directly into their books. Besides, a teacher can use everyday materials to start with, like pictures from magazines, books or newspapers. In short, almost anything can be needed to launch discussions and to create the reading texts.

Regardless of various procedures of the LEA, the following discussion refers to several usual alternative techniques of the LEA in terms of the learners reading level.

\subsection{Elementary Reading Program}

\subsubsection{Dictated Experience Story}

Based on a common experience such as a recent movie he or she has seen, a daily activity, a special event or colourful picture, individual student or group dictates a short passage to the teacher who records it on the board or a large sheet of paper. If a student dictates a statement that does not conform to regular English usage, the teacher corrects the statement orally and writes it in its correct form. This is done so that from the start, the story will be a good model of English usage as it is used for reading instruction

After the whole story had been written the teacher reads it back to the students aloud. As he or she reads, he or she sweeps his or her hand under each word so that the students can see where each word begins and ends, so that reading is done from left to right. After that, the student reads the story with the teacher's help. Pronunciation errors are corrected quickly by the teacher by pronouncing the right one. The difficult words are picked out and printed into small cards for recognition drill.

Next, discuss written language elements and principles within the story by pointing out capital letters, proper names, contraction, and abbreviation among other written language.

Then, have the student read the story aloud. Supply help with word quickly to maintain fluent reading.

Later, the students' dictated stories are stapled into book form. The students will have very positive feeling on producing their own text. The students rehearse their stories and read them to the teacher, friend, small groups, or the whole class.

As a follow-up activity, sentence completion can be derived from the story, and the students are asked to recognize words which are randomly pointed out.

\subsubsection{Gossip Game}

The gossip game is the activity in which the student writes a question and passes the piece of paper to the student on the right, who then answer the question on different paper, and writes another question for the next student.

Then the question and answer paper are put in different box. After that, the teacher asks two students to take the paper. It becomes a fun for the class since the answer does not match the question or the answer matches the question.

\subsection{Intermediate Reading Program}

Free writing is applied for the students in this level. Individual student writes a topic which is interesting to him or her. Revisions are made by having students' works in the small group. The stories are then shared and read as a class. After the writer reads his or her story, he or she asks some questions about the story content to the listeners. The teacher might also formulate some questions related to the student's story.

There are some follow-up activities that can be applied to extend the students comprehension from their stories, such activities may include:

- Give students one of revised story from which words have been omitted. Have them fill in the omitted words. 
- Select the student's stories with clear assessment of events. Have students make a time line for that story, listing the events in chronological order.

- Have two or more students read and composed a new story on the same topic. Then have them cut apart from their respective stories and compose a new story, combining statements from each the original stories. They will have to reorder details, delete some repetitious statements, and consider the best way to organize the new story.

- Keep a separate folder in the classroom for extra copies of students writing. Encourage student to browse through these and read them to one another.

Although there are many variations of the LEA, only one rule remains the same-use the students' vocabulary, language pattern and background of experiences to create the reading text and make reading a meaningful process.

\section{METHODOLOGY}

\subsection{Method of the Study}

In this study, the experimental method was used. The term experimental method means an approach to educational research in which an idea or hypothesis is tested or verified by setting up situations in which the relationship between subjects or variables can be determined [14].

To carry out the method, the writer did an experiment by doing the actual teaching to the sample students. The sample students were divided into two groups based on their scores in the pretest so that these two groups were considered on the same level of reading comprehension ability. In this study, the LEA was performed in group A. Meanwhile the teaching of reading by using the traditional approach was applied in group B. The design of pretest posttest factorial design can be seen in table 1 .

Table 1 Factorial Design

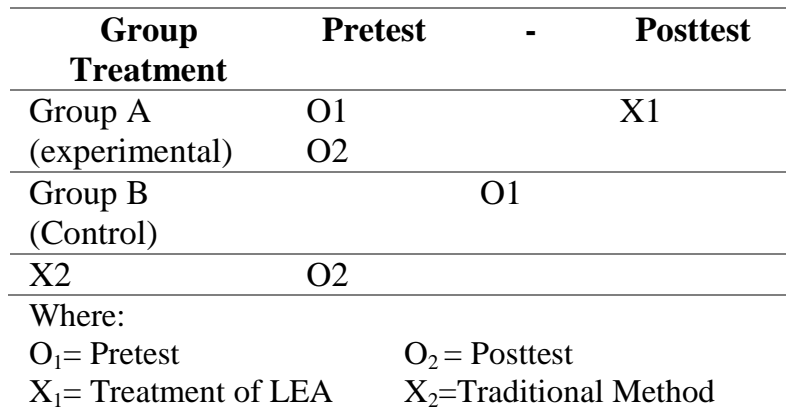

\subsection{Population and Samples}

The population of this study was the third semester of engineering students of State Polytechnic of Sriwijaya of
2018/2019. The total number of the population was 176 students comprising 7 classes.

In this study the writer use stratified random sampling. Stratified random sampling is the form of random sampling in which a population is first divided into subgroups or strata and subjects are selected from each group. The whole number of the sample was 52 students. The description of the sample students is shown in the Table 2.

Table 2 The Distribution of the Sample

\begin{tabular}{|c|c|c|}
\hline No & Class & Number \\
\hline 1 & Group A & 26 \\
\hline 2 & Group B & 26 \\
\hline & Total & 52 \\
\hline
\end{tabular}

\subsection{Techniques for Collecting the Data}

Two tests are used as the instruments because they are considered the most reliable way and easy to use for finding out the teacher's and the students success in teaching and learning and the difficulties as well. In this study, the writer gives a pretest and a posttest. The pretest is given before the experiment, while the posttest was given after the experiment. The questions of both two tests were the same. The instrument consisted of five stories which were taken from several book. There were 40 questions in the five stories and they were all in the form of multiple choice questions). This instrument had been tried out for its reliability. In this case, the instrument is 25 third semester students of State Polytechnic of Sriwijaya before the real experiment is conducted. The result of this preliminary study was analyzed by using KR 21 formula

\subsection{Techniques for analyzing the Data}

In analyzed the data collected from the test, the writer divides the students score into two groups.

Group A: The scores of the pretest and posttest of the students who learned reading by using the LEA.

Group B: The scores of the pretest and posttest of the students who learned reading by using the traditional approach.

In this study, the writer presented the data distribution of each test (pretest and posttest) of both two groups in the form of the raw scores. Besides that, the writer also analyzes the data statistical by using $t$ test formula.

In statistical analysis, the writer compares the calculation of t-statistics and the value of the t-table. If the value of tstatistics was higher than the value of the t-table, it means that the first hypothesis was accepted. On the other hand, if the value of t-statistics was lower than the value of the $t$ table, it means that the first hypothesis was rejected. 
Second, to determine whether the second hypothesis was accepted or rejected, the writer also calculates the mean scores of the pretest and the posttest of both two group. Then, he applies the t-test formula for both group. If the value of t-statistics was higher than the value of the t-table, it means the second hypothesis was accepted. On the other hand, if the value of the t-statistic was lower than the value of the t-table, it means the second hypothesis was rejected. The students' progress between the two groups was compared to see which group had made the better progress or which of the two approaches was more effective.

\section{FINDINGS AND INTERPRETATION}

\subsection{Findings}

\subsubsection{Data Distributions}

The data collected from the test pretest and posttest were classified into two groups. Group A consisted of the scores of the pretest and posttest of the students who learned reading by using the language Experience Approach. Meanwhile, group B consisted of the scores of the pretest and posttest of the students who learned reading by using the traditional approach. The four tables below present the score distribution of pretest and posttest of each group.

a) The Pretest Scores of the Students in Group A

Based on the result of the pretest scores of the students in group $\mathrm{A}$, the highest score was 75 and the lowest score was 46. The distribution of the pretest score of the students in group A is shown in Table 3.

Table 3 The Score Distribution of the Pretest of Group A

\begin{tabular}{|c|c|c|}
\hline Interval & Frequency & Percentage \\
\hline $91-100$ & 0 & $0 \%$ \\
\hline $81-90$ & 0 & $0 \%$ \\
\hline $71-80$ & 3 & $11,5 \%$ \\
\hline $61-70$ & 9 & $34,6 \%$ \\
\hline $41-60$ & 14 & $53,9 \%$ \\
\hline
\end{tabular}

In which:

$81-100=$ high $\quad 61-80=$ average $\quad 41-60=$ low

Table 3 above shows that none of the students got high score. $12(46.1 \%)$ of them got average score, and most of them $(53.8 \%)$ got low score. It proves that more than half $(53.8 \%)$ of the students still had unsatisfactory comprehension.

b) The Pretest Scores of the Students in Group B

Based on the pretest scores of the students in group B. It was found that the highest score was 75 and the lowest score was 47 . The distribution of the pretest scores of the students in group B can be seen in Table 4 .
Table 4 The Score Distribution of the Prestest of Group B

\begin{tabular}{|c|c|c|}
\hline Interval & Frequency & Percentage \\
\hline $91-100$ & 0 & $0 \%$ \\
\hline $81-90$ & 0 & $0 \%$ \\
\hline $71-80$ & 4 & $15,4 \%$ \\
\hline $61-70$ & 9 & $34,6 \%$ \\
\hline $41-60$ & 13 & $50 \%$ \\
\hline
\end{tabular}

Based on Table 4 above, it is shown that $13(50 \%)$ of the students got average score and $13(50 \%)$ of them got low score and none of them got high score. It means that the students' achievement in reading comprehension was also low. In conclusion the students reading comprehension achievement of both group $\mathrm{A}$ and group B (see Table 4 \& 5) was still unsatisfactory.

c) The Posttest Scores of the Students in Group A Having analyzed the students' posttest scores from group A, it was found that the highest score was 94 and the lowest score was 62 . Table 5 presents the score distribution of the posttest of group A.

Table 5 The Score Distribution of the Postest of Group A

\begin{tabular}{|c|c|c|}
\hline Interval & Frequency & Percentage \\
\hline $91-100$ & 3 & $11 \%$ \\
\hline $81-90$ & 6 & $23,1 \%$ \\
\hline $71-80$ & 7 & $26,9 \%$ \\
\hline $61-70$ & 10 & $38,5 \%$ \\
\hline $41-60$ & 0 & $0 \%$ \\
\hline
\end{tabular}

Table 5 shows that $9(34.6 \%)$ of the students got higher score. The rest or $17(65.4 \%)$ got average score, and none of them got low score. Most of the students got the score above 60 and none of them got the score below 60 .

d) The Post test Scores of the students in Group B

Based on the posttest scores of the students in group B, it was found that 82 was the highest score and 57 was the lowest score. For further description of the posttest scores of the students in group B. The score distribution of the students' posttest is as follows.

Table 6 The Score Distribution of the Posttest of Group B

\begin{tabular}{|c|c|c|}
\hline Interval & Frequency & Percentage \\
\hline $91-100$ & 0 & $0 \%$ \\
\hline $81-90$ & 5 & $19,2 \%$ \\
\hline $71-80$ & 6 & $23,1 \%$ \\
\hline $61-70$ & 10 & $38,5 \%$ \\
\hline $41-60$ & 5 & $19 \%$ \\
\hline
\end{tabular}

From 26 students, there were $5(19.2 \%)$ of them who got high score, $16(61.6 \%)$ of them got average score and 5 
$(19.2 \%)$ of them got low score. It shows that most of the students got average score $(61.6 \%)$, only a few of them got high score $(19,2 \%)$, and also a few of them $(19,2 \%)$ got low score.

In conclusion, the students reading comprehension achievement after applying the Language Experience Approach was higher compared with their reading comprehesion achievement before the experiment. It also proves that the students had made progress after they learned reading by using the Language Experience Approach. Meanwhile, the students reading comprehesion achievement in group B remained low (see table $4 \& 6$ ). In other words, the students only made a little progress after they learned reading by using the traditional approach.

\subsubsection{Statistical Analysis}

Having classified the data (the scores of pretest and posttest) into two groups, the writer analyzed them in order to know the significant difference between the two groups, the students progress of each group, and the effectiveness of such an approach. To do these, t-test formula was used.

a) The Significant Difference between the Two Means of Scores from Group A and B

The t-test was used to verify the hypotheses. The following table consist of the data of pretest and posttest of Group A and Group B.

Table 7 The Data of the Pretest and Posttest of Group A $(\mathrm{N}=26)$ and Group $B(\mathrm{~N}=26)$

\begin{tabular}{|c|c|}
\hline Group A & Group B \\
\hline$\sum \mathrm{X}_{1}=352$ & $\sum \mathrm{X}_{2}=129$ \\
\hline $\mathrm{M}_{1}=13.5$ & $\mathrm{M}_{2}=5$ \\
\hline $\mathrm{S}_{1}{ }_{1}=113.8$ & $\mathrm{~S}_{2}{ }_{2}=69.9$ \\
\hline
\end{tabular}

In which:

$\sum \mathrm{X}_{1}=$ the sum of the scores difference between post test and pre-test in group A.

$\sum \mathrm{X}_{2}=$ the sum of the scores difference between

$\mathrm{M}_{1}=$ the mean scores between post-test and pre-test in group A

$\mathbf{M}_{2}=$ the mean scores between post-test and pre-test in group B

$\mathrm{S}^{2}{ }_{1}=$ the variance of scores between post-test, and pre-test in group $\mathrm{A}$.

$\mathrm{S}_{2}^{2}=$ the variance of scores between post, test, and pre test in group B.

After calculating the data above into t-test formula, the value of gained $t_{1}$ is 3.3. At the level significance of 0.05 , it was found that the $t$ table value at $d f=25$ for the two tailed test is 2.060. Therefore, it can be concluded that the first hypothesis was accepted because the computed $t$ score statistic $\left(t_{1}=3.3\right)$ was higher than the table $t$ value $(0.05=$ 2.060). b) The Progress Analysis of Each Group

To verify that the mean score of group A was statistically significant different from the mean scores of group B. The writer also used t-test formula. This was done to find out which of the two groups made higher progress. The following table consists of the data of pretest and posttest in group A. The description of the pretest and posttest scores.

Table 8 The Data of Pretest and Posttest of Group A

\begin{tabular}{|c|c|}
\hline Pretest & Posttest \\
\hline$\sum \mathrm{X}_{1}=1574$ & $\sum \mathrm{X}_{2}=1926$ \\
\hline $\mathrm{M}_{1}=60.5$ & $\mathrm{M}_{2}=74.1$ \\
\hline $\mathrm{S}_{1}{ }_{1}=54,2$ & $\mathrm{~S}_{2}{ }_{2}=88.5$ \\
\hline
\end{tabular}

Based on t-score statistic, the value of gained $t\left(t_{2}\right)$ was 5.9. In other words, the value of gained $t_{2}$ was bigger than the value of the t-table (a 0.05 at $\mathrm{df}=25$ for one tailed test is 1.708). It means that the students in group A got better scores compared with their scores in pretest. It proves that the students had made higher progress after learning reading comprehension by using the Language Experience Approach.

Meanwhile. t-score statistics of group B was 2.8 and the value of the t-table at the level significance 0.05 at $\mathrm{df}$ 25 is 1.708. It shows that the students also made higher progress after learning reading comprehension through traditional approach but it was not as high as that of group A. The following table consists of the data of pretest and the post test of group B.

Table 9 The Data of Pretest and Posttest of Group B

\begin{tabular}{|c|c|}
\hline Pretest & Posttest \\
\hline$\sum \mathrm{X}_{1}=1603$ & $\sum \mathrm{X}_{2}=1771$ \\
\hline $\mathrm{M}_{1}=61.7$ & $\mathrm{M}_{2}=68.1$ \\
\hline $\mathrm{S}_{1}^{2}=61.8$ & $\mathrm{~S}_{2}{ }_{2}=71$ \\
\hline
\end{tabular}

c) Effectiveness of an Approach

Based on the progress analysis, it was found that $t_{2}$ was 5.9 and $t_{3}$ was 2.8. In other words, both $t_{2}$ and $t_{3}$ were higher than the t-table value (1.708). Since $t_{2}$ score statistics (5.9) was higher than $t_{3}$ score statistics, the second hypothesis is accepted.

\subsection{Interpretation}

Based on the results of this study, it could be said that the Language Experience Approach is a suitable reading approach to be used in teaching reading comprehension because it can develop the students' motivation and reading ability. The students who learn reading by using this approach have a stronger desire to interact as they are interested in their peers writing. They share their ideas with each other as a class: they want to know what each other has decided to share. 
However, to teach reading by using the LEA, the teacher needs a lot of time. Therefore, in applying this reading approach, the teacher should have a good preparation and performance in order to teach effectively. Besides the teacher should also be able to control the class because the attraction during the learning activity tends to be noisy.

\section{CONCLUSIONS}

After doing the simple experiment in teaching reading comprehension by using the LEA and the traditional approach, it is concluded that LEA approach was more effective than traditional approach in teaching reading comprehension. It can be seen from the result of two means scores from group A and group B. Therefore, this reading approach could be considered as one of the plausible approaches to be used in TEFL. In teaching and learning reading, reading approaches play an important role because they facilitate students read efficiently.

\section{REFERENCES}

[1] Patel, M, Jain, P, English Language Teaching. Jaipur. Sunrise Publishers \& Distributors, 2008.

[2] Duffy, G. G, Explaining Reading: A Resource for Teaching Concepts, Skills, and Strategies. New York: The Guilford Press, 2009.

[3] Grabe, W, Reading in a Second Language: Moving from Theory to Practice. Cambridge University Press, 2009.

[4] Wolf, M, Tales of Literacy for the $21^{\text {st }}$ Century: The literary agenda. OUP Oxford, 2016.

[5] Howards, M, Reading Diagnosis and Instruction: An Integrated Approach. Englewood Cliffs. NJ: Prentice Hall Company, 1989
[6] Heilman, A, W, et al, Principles and Practices of Teaching Reading. Columbus, OH: A Bell \& Howell Company, 1981.

[7] Cheek, et al, Reading for Success in Elementary School. Or lando, FLE Holt, Rincart. and Winston, Inc, 1989.

[8] Barnizt, G, J, Reading Development of Nonnative Speakers of English. Orlando, FL: Harcourt Brace Jovanovich, Inc, 1985.

[9] Alderson, C, J, Assessing Reading. United Kingdom: Cambridge University Press, 2000.

[10] Marian, V. Blumenfeld, H.K., \& Kaushanskaya, M, "The Language Experience and Proficiency Questionnaire (LEAP-Q): Assessing language profiles in bilinguals and multilinguals". Journal of Speech, Language, and Hearing Research, 50(August), 940, 2007.

[11] Bromley, K, D, Language Arts: Explorine Connection. Boston, MA: Allyn and Bacon, 1992.

[12] Rubin, D, A Practical Approach to Reading. Boston, MA: Al1yn and Bacon, Inc, 1993.

[13] Tierney, R, J, et al, Reading Strategies and Practices: Guide for improving instruction. Boston, MA: Allyn and Bacon, Inc, 1980.

[14] Richards, J, et al, Longman Dictionary of Applied Linguistics. Hongkong: Longman Group Limited, 1989.

[15] Coco, M. I., \& Keller, F, "Integrating mechanisms of visual guidance in naturalistic language production". Cognitive Processing, 16 (10), 131 150. https://doi.org, 2015. 